InterAção | 43

\title{
A ATUAÇÃO DO BRASIL NO ÓRGÃO DE SOLUÇÃO DE CONTROVÉRSIAS DA OMC E 0 LUGAR DO DIREITO NA PEB
}

\author{
Cristine Koehler Zanella ${ }^{1}$ \\ Inaê Siqueira de Oliveira²
}

Resumo

$\mathrm{O}$ reconhecimento de que o direito é um instrumento político distingue a Política Externa Brasileira (PEB) desde os tempos coloniais. Modernamente, essa característica da PEB pode ser aferida por meio da atuação do Brasil junto ao Órgão de Solução de Controvérsias (OSC) da Organização Mundial do Comércio. O artigo analisa, valendo-se fundamentalmente do método histórico, o percurso do comércio internacional durante o século XX, marcado por sucessivas e acentuadas mudanças, e a atuação do Brasil junto ao OSC. Ao fazê-lo, demonstra como essa instrumentalização do direito pela $\mathrm{PEB}$, ao mesmo tempo em que reduz as assimetrias do poder mundial, salvaguarda os interesses nacionais e faz com que o Brasil cresça dentro do sistema multilateral de comércio, impulsionando a sua projeção internacional.

\footnotetext{
1 Doutoranda em Estudos Estratégicos Internacionais na Universidade Federal do Rio Grande do Sul (UFRGS). Professora no Centro Universitário Ritter dos Reis (UniRitter - Porto Alegre). Membro do Núcleo de Pesquisa em Relações Internacionais de Santa Maria (PRISMA) - Eixo de Globalização e Integração Regional. E-mail: cristinezanella@gmail.com 2 Graduanda em Direito na Faculdade de Direito de Santa Maria (Fadisma). E-mail: oliveira.inae@gmail.com
} 
44 | InterAção

Palavras-chave: Comércio internacional, Órgão de Solução de Controvérsias, Política Externa Brasileira

Abstract

Brazilian Foreign Policy (BFP) uses law as a political instrument since 1750's, and nowadays this BFP's characteristic appears through Brazilian participation in World Trade Organization Dispute Settlement System (DSS). The purpose of this article is to analyze, basically through the historical approach, how international trade has been transformed during the XX century and how law have been used by BFP to the country's growth on international trade system. Through DSS Brazil defends its national interest, reduces global power asymmetries and boosts the Brazilian international projection.

Keywords: International trade, Dispute Settlement System, Brazilian Foreign Policy

\section{INTRODUÇÃO}

O comércio internacional iniciou o século XX sob os efeitos protecionistas das crises que sucederam a Primeira Guerra Mundial e o encerrou com a criação de uma Organização Mundial do Comércio (doravante OMC ou Organização). Entre o surto protecionista da década de 30 e os acordos de livre comércio dos anos 90, a maior guerra da história moderna aconteceu, o mundo viu-se dividido por ideologias e a ordem internacional se transformou. $\mathrm{O}$ percurso do 
comércio internacional no século XX foi marcado por emblemáticos pontos de inflexão, um caminho de curvas acentuadas no qual alguns paradigmas ruíram e outros foram erigidos. A defesa do comércio pelas armas deu lugar, com a adoção do Acordo Geral sobre Tarifas e Comércio, à diplomacia. A diplomacia, por sua vez, passou a ser acompanhada pelo direito a partir da criação da OMC - que trouxe consigo aquele que tem sido considerado o mais poderoso tribunal internacional existente. O advento do Órgão de Solução de Controvérsias (OSC) representou o reforço do controle jurídico sobre o sistema multilateral de comércio, fazendo com que o direito se tornasse uma poderosa ferramenta em um mundo outrora condicionado apenas pelas leis da selva econômica.

Em meio a muitas assimetrias e desequilíbrio de poder, a atuação do Brasil no sistema multilateral de comércio reforça um elemento de continuidade da Política Externa Brasileira: a utilização do direito como instrumento político. A atuação no Brasil no comércio internacional demonstra que o país se vale do direito, das normas internacionais - e, na área comercial, isso significa dizer que o Brasil utiliza fundamentalmente o Órgão de Solução de Controvérsias - para salvaguardar os seus interesses e reduzir as assimetrias do sistema multilateral de comércio. Isso contribuiu para que o Brasil conquistasse um papel de liderança entre os Estados-membros da $\mathrm{OMC}$, abrindo caminho até à mesa de negociações do comércio internacional.

Ao discutir a transformação do comércio internacional durante o século XX e a atuação do Brasil no Órgão de Solução de Controvérsias, este artigo analisa como a utilização do direito como 
46 | InterAção

um instrumento político impulsionou a projeção brasileira no atual sistema multilateral de comércio.

\section{Das armas ao direito: 0 tortuoso percurso do comércio internacional no século XX}

Nos primeiros cinquenta anos do século passado, a guerra foi utilizada como instrumento para garantir interesses políticos e econômicos - não por outra razão esse curto intervalo de tempo é caracterizado por duas guerras mundiais. Além disso, a década de 30 foi marcada por um surto protecionista ao redor do globo. Como aponta Blustein, a edição da Lei Smoot-Hawley - que aprovou as mais altas tarifas da história americana - pelos Estados Unidos “desencadeou um ciclo mundial de retaliações e contrarretaliações” (2010, p. 40). Os Estados reagiram à crise de 29 protegendo seus mercados e suas moedas, criando barreiras ao comércio internacional e restringindo quantitativamente as importações. A "Guerra de Tarifas" iniciou um sistema de retaliações comerciais recíprocas - o que só acentuou a crise econômica ${ }^{3}$.

Foi quase ao final da Segunda Guerra Mundial que veio, paradoxalmente do mesmo país que editara a infame Lei Smoot-Hawley, a proposta do livre comércio sob a justificativa de que isso proporcionaria a recuperação econômica e o desenvolvimento. Com isso, formulou-se o paradigma de uma nova ordem comercial liberal, consubstanciado na

3 0s parceiros comerciais dos EUA reagiram à Lei Smoot-Hawley editando as suas próprias: a França aumentou as tarifas sobre alimentos de 19\% (1927) para 53\% (1931); as da Alemanha foram de $27 \%$ para $82 \%$; as da Itália de $24 \%$ para $66 \%$, entre outros países (BLUSTEIN, 2010). 
InterAção | 47

emblemática Conferência de Bretton Woods ${ }^{4}$. Nela, discutiu-se a criação de instituições econômicas a fim de evitar que os erros cometidos no passado voltassem a acontecer - em razão da Conferência surgiram o Fundo Monetário Internacional (FMI) e o Banco Internacional para a Reconstrução e o Desenvolvimento (BIRD), pilares do que viria a ser conhecido como "Sistema de Bretton Woods".

Durante o mesmo período (1944-1947), discutiu-se a necessidade da criação de uma Organização Internacional do Comércio (OIC), cujo objetivo seria estabelecer diretrizes e regular o renovado comércio internacional. Divergências entre grandes potências, entretanto, dificultaram as negociações, ao que se somou uma barreira decorrente da conjuntura política interna norte-americana ${ }^{5}$, principal ator do comercio internacional à época. Em lugar de uma organização internacional, adotou-se em 1947, por meio de um Protocolo de Aplicação Provisória (PPA) ${ }^{6}$, o Acordo Geral sobre Tarifas e Co-

4 A Conferência de Bretton Woods foi realizada entre os dias $1^{\circ}$ e 22 de julho de 1944 em New Hampshire, nos Estados Unidos. Por ocasião deste encontro, criaram-se os pilares do que viria a ser conhecido como "Sistema Bretton Woods": um modelo de ordem econômica, baseado em um esquema de paridades cambiais fixas (mas ajustáveis), fundamentadas no padrão dólar-ouro, que tinha como objetivo de regular a política econômica internacional.

50 s representantes dos Estados Unidos negociavam sob autorização do Congresso, que expiraria em junho de 1948 e dificilmente seria renovada caso a nova composição do Congresso fosse majoritariamente republicana. Devido à dificuldade nas negociações da Carta Constitutiva da OIC ficou claro que ela não seria concluída antes desta data - 0 que motivou a adesão dos Estados Unidos (à época governado por um democrata, Harry Truman) ao GATT em 30 de outubro de 1947 (VAN DEN BOSSCHE, 2005).

60 Protocolo de Aplicação Provisória, em fato, nunca foi substituído e vigorou até a criação da OMC, em 1995 - 0 que totaliza quarenta e sete anos de "aplicação provisória" (JACKSON, 2006). 
48 | InterAção

mércio (mais conhecido por sua sigla em inglês: GATT). O GATT, concebido como um tratado, continha o que seria a segunda e a terceira partes da Carta Constitutiva da $\mathrm{OIC}^{7}$ : esta referente a cláusulas gerais sobre obrigações tarifárias e aquela relacionada à negociação multilateral para a redução recíproca de tarifas.

Para que se conseguisse reduzir tarifas foram realizadas sucessivas conferências entre os Estados que participavam do GATT denominadas “Rodadas”. Durante a vigência do Acordo (1947-1994), o livre comércio obteve um significativo avanço: dentre as oito rodadas realizadas no âmbito do GATT, seis dedicaram-se à redução de direitos aduaneiros sobre produtos industrializados, resultando num decréscimo tarifário médio de 40\% para 4\% (VAN DEN BOSS$\mathrm{CHE}, 2005)^{8}$. Em que pese o avanço no comércio internacional, este ainda era guiado por vias demasiadamente diplomáticas, evidenciando o desequilíbrio de poder entre os Estados. Em razão disso, durante a Rodada Uruguai, iniciada em 1986, começou a discutir-se o reforço do controle jurídico sobre as relações comerciais internacionais. $\mathrm{O}$ objetivo era garantir mais estabilidade e equidade ao sistema, inibindo o uso indiscriminado e abusivo do poder econômico, prática notadamente utilizada em situações de litígio. $\mathrm{O}$ processo culminou

7 A Carta Constitutiva da OIC, também conhecida como "Carta de Havana", foi finalizada em 1948 e, apesar de repetidamente submetida ao Congresso Americano, não foi aprovada. Como os EUA eram os responsáveis pela maior parte do comércio internacional, a sua não adesão à Organização comprometeu a sua existência.

8 Não se pode ignorar, entretanto, que estes avanços não se deram de forma simétrica para todas as nações que aderiram ao GATT. A disparidade entre as regras aplicadas aos produtos industriais e agrícolas (que ainda hoje existe) é apenas um dentre os tantos exemplos de desnível no terreno da disciplina do comércio internacional (AZEVEDO; CARDOSO, 2007). 
InterAção | 49

na criação da $\mathrm{OMC}$, cujo Acordo Constitutivo ${ }^{9}$ foi assinado por 112 países em 1994, à ocasião do término da Rodada Uruguai ${ }^{10}$. A nova organização simbolizou uma profunda transformação no comércio internacional, uma vez que a postura power-oriented deu lugar à postura ruled-oriented. Os contornos jurídicos se delinearam em um importante elemento que acompanhou a criação da OMC: o Órgão de Solução de Controvérsias.

A criação do Órgão de Solução de Controvérsias chancelou a

9 0s Acordos de Marraqueche, assinados por ocasião da Conferência na cidade de mesmo nome, encerram a Rodada Uruguai e têm adesão obrigatória a todos que desejassem se tornar membros da Organização que surgia - eles formavam o chamado single package. São eles: o Acordo Constitutivo da OMC, os Acordos Multilaterais de Comércio de Bens - que mantém as obrigações legais previstas no GATT-47 -, o Acordo Geral sobre o Comércio de Serviços, o Acordo sobre Aspectos de Direitos de Propriedade Intelectual Relacionados ao Comércio, o Mecanismo de Exame de Políticas Comerciais e o Entendimento Relativo às Normas e ao Procedimento sobre Solução de Controvérsias (ESC). (CARVALHO, 2006).

10 Apesar de não ser um dos propósitos originais da Rodada Uruguai - a declaração de Punta del Este apenas reconhecia a necessidade de reformas institucionais no sistema GATT - a delegação canadense propôs formalmente, em abril de 1990, a criação de uma organização que administraria os diversos instrumentos legais relacionados ao comércio internacional. Neste mesmo sentido, a Comunidade Europeia propôs, em julho do mesmo ano, a criação da "Organização Multilateral do Comércio". As reações a estas propostas foram mistas, e ao término da Rodada Uruguai, previsto para dezembro 1990, não havia nenhuma definição sobre o tema. No ano seguinte as negociações recomeçaram, e, desta vez, Europa, Canadá e México submeteram, em conjunto, a proposta de uma organização internacional que regulasse a atividade comercial, denominada "Organização Multilateral do Comércio". Os EUA adotaram uma posição contrária, mas, já em 1993, a maior parte dos participantes da Rodada Uruguai preparava-se para ingressar na organização, o que tornava a posição norte-americana extremamente isolada. Finalmente, em dezembro de 1993, para a surpresa de muitos, os Estados Unidos concordaram com a criação da organização. Impuseram, entretanto, uma condição: a alteração do nome para Organização Mundial do Comércio. (VAN DEN BOSSCHE, 2005). 
50 | InterAção

postura ruled-oriented nas relações comerciais internacionais. De jurisdição compulsória para todos os membros da Organização Mundial do Comércio, o OSC tem competência para decidir sobre qualquer disputa entre membros da OMC que envolvam direitos e obrigações decorrentes dos acordos e princípios da Organização - isso significa que 155 Estados estão obrigatoriamente vinculados à jurisdição do Órgão de Solução de Controvérsias ${ }^{11}$. Suas decisões funcionam por consenso reverso - é necessário que todos os países da OMC discordem de uma sentença para que ela não seja aplicada - o que confere às decisões do OSC execução praticamente automática (CARVALHO, 2006). Não por outra razão, o Órgão de Solução de Controvérsias é justificadamente descrito como um dos mais importantes e poderosos tribunais internacionais. Nas palavras de John H. Jackson, professor de Direito na Universidade de Georgetown e ex-consultor jurídico do Escritório do Representante de Comércio dos Estados Unidos:

This DSS (Dispute Settlement System) is unique in international law and institutions, both at present and historically. It embraces mandatory exclusive jurisdiction and virtually automatic adoption of dispute settlement reports, extraordinary for an institution with such broad-ranging competence and responsibilities as the WTO - virtually every aspect of economic regulation and policy is touched upon at least potentially, if not actually, and

11 Dados referentes a maio de 2012, disponíveis no site oficial da OMC, indicam que atualmente a Organização Mundial do Comércio possui 155 membros e 29 países observadores (WTO, 2012a). Mas há que se considerar que a Rússia confirmou sua adesão à organização dia 21 de julho de 2012 - que começará a valer 30 dias após a ratificação, quando a OMC passará, então, a contar com 156 membros e 28 países observadores (RUSSIA TODAY, 2012). 
InterAção | 51

it is already imposing obligations on 148 nations (out of 192 recognized), comprising 93 percent of world trade, and 87 percent of world population. The DSS has been described as the most important and most powerful of any international law tribunals, although some observers reserve that primary place to the World Court (International Court of Justice). Even some experienced World Court advocates, however, have been willing to concede that primacy under some criteria to the WTO DSS (2006, p. 163).

O adensamento da juridicidade no sistema multilateral de comércio pôs fim à possibilidade, várias vezes adotada durante a vigência do GATT, de um Estado infrator rejeitar unilateralmente uma decisão contrária a ele. Portanto, ainda que se tenha preservado o caráter político-diplomático do OSC e por mais que a OMC não possa forçar seus membros - que são nações soberanas - a cumprir uma decisão do OSC, o direito dos reclamantes vitoriosos de impor medidas retaliatórias (como o aumento punitivo da tarifa sobre os produtos do país infrator até o valor limite do prejuízo causado pela infração) garante mais segurança e previsibilidade às relações comerciais internacionais à medida que inibe muitos impulsos protecionistas e práticas desleais.

\section{Ao direito como arma:0 percurso do Brasil até à mesa de negociação do comércio internacional}

Nas palavras de Paul Blustein, "esse acordo [do OSC] evita que as controvérsias relativas ao comércio se tornem desnecessariamente destrutivas, assim como qualquer sistema baseado nos princípios do direito ajuda a conter as leis da selva” (2010, p. 44). O papel do Órgão 
de Solução de Controvérsias, entretanto, parece ir além disso: mais do que ajudar "a conter as leis da selva", o adensamento jurídico do sistema multilateral de comércio consubstanciado no advento do OSC permitiu que países em desenvolvimento apresentassem demandas comerciais importantes que não teriam força - política e econômica para defender de outra maneira. Dentre os países em desenvolvimento, aquele que notadamente mais se utilizou do OSC - ou seja, do direito - como instrumento para garantir seus interesses foi o Brasil.

O reconhecimento de que o direito é um instrumento de política acompanha a história da Política Externa Brasileira (PEB). O Brasil consolidou a maioria de suas fronteiras não pela força das armas, senão pelos argumentos jurídicos de seus diplomatas. A construção da teoria do uti possidetis de fato (quem possui de fato, deve possuir de direito) resolveu uma série de disputas de fronteira desde os tempos coloniais, e a atuação de diplomatas como Alexandre Gusmão e José Maria Paranhos Júnior, o Barão do Rio Branco, está vastamente documentada, sendo um dos significativos exemplos do relevo do direito nos movimentos da PEB.

A utilização do direito como instrumento político, que se fez notar desde o século XVIII quando o objetivo era consolidar as fronteiras do país, é uma característica da PEB que permaneceu e se redesenhou no tempo. Hoje pode ser vislumbrada ao se analisar a atual projeção do Brasil no comércio internacional.

O Brasil é considerado um dos principais atores do sistema multilateral de comércio, um major player. Isso não se explica por sua participação no comércio internacional, senão por sua importância dentro da Organização Mundial de Comércio. Esta importância é o resultado 
de ações pautadas pela consciência de que o multilateralismo é a melhor via para inserção internacional do país, conjugada à utilização do direito como instrumento para diminuir as assimetrias do sistema multilateral de comércio. Segundo o Ex-Ministro das Relações Exteriores Celso Amorim, "é melhor trabalhar com a regra imperfeita, tentar melhorar a regra e, progressivamente, ir modificando, do que ficar fora disso e se expor à lei da selva que é o unilateralismo" (2007, p. 18).

Da valorização do multilateralismo enquanto forma e do direito enquanto instrumento político resulta a contundente atuação brasileira no Órgão de Solução de Controvérsias da OMC. Como pode ser visto na tabela abaixo, a participação do Brasil como reclamante no OSC demonstra que a utilização do direito como meio para diminuir as assimetrias do poder mundial e salvaguardar os interesses nacionais é uma característica da Política Externa Brasileira que se manifesta nitidamente na condução da política comercial. Por mais que o Brasil não tenha grande representatividade no comércio internacional (o Brasil, em 2011, somou aproximadamente 1,35\% do total de importações e exportações realizadas no mundo - um número inferior ao de países como Índia, México e Austrália), é o quarto maior reclamante no Órgão de Solução de Controvérsias, apenas superado por Estados Unidos, União Europeia e Canadá.

A Austrália, país cuja representação no comércio internacional é uma das que mais se aproxima da brasileira, é responsável por $1,14 \%$ das reclamações levadas ao OSC - um número bastante inferior ao percentual de reclamações feitas pelo Brasil, que responde por 5,68\% do total de 440 demandas feitas no OSC. Há também que se considerar que a Índia e a China, dois países cujo crescimento econô- 
mico tem atraído os olhares do mundo, atuam como reclamantes em $4,32 \%$ e 2,05\% dos casos do OSC respectivamente, apesar de terem maior representatividade no comércio internacional do que o Brasil.

Tabela - Representatividade dos países selecionados no comércio internacional e participação como reclamante no Órgão de Solução de Controvérsias

\begin{tabular}{|c|c|c|c|}
\hline Membro da OMC & $\begin{array}{l}\text { Representatividade } \\
\text { no comércio } \\
\text { internacional* }(\%)\end{array}$ & $\begin{array}{l}\text { Casos em que } \\
\text { aparece como } \\
\text { reclamante no } \\
\text { OSC }\end{array}$ & $\begin{array}{l}\text { Participação como } \\
\text { reclamante sobre o } \\
\text { número de casos do } \\
\text { OSC (\%) }\end{array}$ \\
\hline União Europeia** & 22,88 & 86 & 19,55 \\
\hline EUA & 10,24 & 97 & 22,05 \\
\hline China*** & 9,95 & 9 & 2,05 \\
\hline Japão & 4,58 & 14 & 3,14 \\
\hline Canadá & 2,50 & 31 & 7,05 \\
\hline Índia & 2,04 & 19 & 4,32 \\
\hline México & 1,94 & 17 & 3,86 \\
\hline Austrália & 1,41 & 5 & 1,14 \\
\hline Brasil & 1,35 & 25 & 5,68 \\
\hline Arábia Saudita & 1,30 & 0 & 0,00 \\
\hline África do Sul & 0,60 & 0 & 0,00 \\
\hline Argentina & 0,43 & 14 & 3,18 \\
\hline Chile & 0,42 & 9 & 2,05 \\
\hline Venezuela & 0,38 & 1 & 0,23 \\
\hline Egito & 0,24 & 0 & 0,00 \\
\hline Peru & 0,23 & 3 & 0,68 \\
\hline
\end{tabular}

* Calculada a partir do fluxo total de importações e exportações no ano de 2011.

** Desconsideradas as reclamações realizadas individualmente pelos países da UE no OSC. *** Único país da lista a não ingressar na OMC em 1995 (o ingresso da China ocorreu em 2001).

Fonte: elaboração própria a partir de "WTO Statistics Database" (WT0, 2012b) e "WT0 Disputle Settlement: The Disputes - Chronological list of disputes cases" (WT0, 2012c). 
InterAção | 55

Além de garantir os interesses comerciais do país, a atuação do Brasil no OSC, mesmo não tendo como tônica a conquista de um importante papel de liderança perante outros países em desenvolvimento e subdesenvolvidos que integram a OMC, conduziu a esse resultado. Como destacou o Representante Permanente do Brasil junto à OMC, Embaixador Roberto Azevêdo, por ocasião da I Conferência Nacional de Política Externa e Política Internacional (CNPEPI), a atuação do Brasil no DS267 (WTO, 2012d), usualmente referido como "Contencioso do Algodão", por exemplo, fez com que o Brasil se tornasse um líder no tema perante os demais Estados-membros da OMC (AZEVEDO; CARDOSO, 2007).

Ao demonstrar capacidade de ação e responsabilidade, o Brasil conquistou um importante papel de liderança entre seus pares e foi legitimado como porta-voz de vários países que, apesar de interesses comerciais muitas vezes contrastantes, têm um grande objetivo em comum: diminuir as assimetrias do sistema multilateral de comércio. Por conta do respeito conquistado internacionalmente por meio de sua atuação no OSC, o país hoje ocupa lugar de destaque à mesa de negociações do comércio internacional ainda que seja pequeno em termos de volume comercial. E é a análise da relação entre a representatividade do Brasil no comércio internacional e a participação do país como reclamante no OSC que oferece as pistas de como o reconhecimento do direito enquanto instrumento político - uma característica da PEB desde os tempos coloniais - serviu para impulsionar a projeção brasileira dentro do sistema multilateral de comércio. 
56 | InterAção

\section{CONSIDERAÇÕES FINAIS}

O caminho percorrido pelo comércio internacional no século XX foi marcado por curvas acentuadas. Em um período de sessenta anos, caminhou-se do protecionismo da década de 1930 à institucionalização do livre comércio, simbolizada na criação da Organização Mundial do Comércio nos anos 1990. Além de ser um libelo ao livre comércio, a OMC trouxe consigo aquele que tem sido considerado o mais poderoso tribunal internacional existente: o Órgão de Solução de Controvérsias, o qual chancelou a postura ruled-oriented, reforçando o controle jurídico em um mundo outrora condicionado apenas pelos preceitos da selva econômica. Foi esse reforço do direito sobre o sistema multilateral de comércio que criou uma possibilidade concreta de redução das assimetrias do poder mundial, tão evidentes na seara econômica - em especial nas situações de litígio.

A análise da participação do Brasil como reclamante junto ao OSC demonstra que a utilização do direito como instrumento político pela PEB redesenhou-se no tempo e hoje impulsiona a projeção brasileira no sistema multilateral de comércio. Os dados indicam que a condição de major player do Brasil no comércio internacional não se justifica por sua representatividade no volume de exportações e importações mundiais, e sim por sua liderança dentro da OMC. Liderança que em grande medida foi conquistada através do reconhecimento obtido pelo país com a sua atuação junto ao OSC.

Em outras palavras: a consciência de que o direito é um instrumento de política caracteriza a Política Externa Brasileira desde os tempos coloniais, quando os objetivos ainda eram consolidar as 
fronteiras do país. Modernamente, a instrumentalização do direito na $\mathrm{PEB}$, evidenciada na atuação brasileira junto ao OSC, contribui para reduzir as assimetrias do poder mundial e, ao mesmo tempo, impulsionar a projeção do país no comércio internacional.

\section{REFERÊNCIAS}

AMORIM, Celso. Discurso do Ministro das Relações Exteriores, Embaixador Celso Amorim. In O Brasil no mundo que vem ai - I Conferência Nacional de Politica Externa e Politica Internacional. Jerônimo Moscardo e Carlos Henrique Cardim (orgs.). Brasília: FUNAG, 2007. pp. 9-28.

AMORIM, Celso. Palestra proferida pelo Ministro das Relações Exteriores, Embaixador Celso Amorim, aos alunos do Instituto Rio Branco. Brasília: MRE, 06 de agosto de 2008. Disponível em: $<$ http:/www.itamaraty.gov.br/sala-de-imprensa/discursos-artigosentrevistas-e-outras-comunicacoes/ministro-estado-relacoes-exteriores/ palestra-proferida-pelo-ministro-das-relacoes >. Acesso em: 22. mai. 2012.

AZEVÊDO, Roberto Carvalho; CARDOSO, Elio de Almeida. Negociações Comerciais Multilaterais - Nova Geografia. In O Brasil no mundo que vem ai - I Conferência Nacional de Política Externa e Politica Internacional. Jerônimo Moscardo e Carlos Henrique Cardim (orgs). Brasília: FUNAG, 2007.p. 37-44.

BLUSTEIN, Paul. Desventuras das naçôes mais favorecidas. Brasília: FUNAG, 2010.

CARVALHO, Evandro Menezes de. Organização Mundial do Comércio: cultura jurídica, tradução e interpretação. Curitiba: Juruá, 2006. 
58 | InterAção

JACKSON, John H. Dispute Settlement and the WTO. In Journal of International Economic Law, Vol. 1, Issue 3, pp. 329-351, 1998.

Sovereignty, the WTO, and Changing Fundamentals of

International Law. New York: Cambridge University Press, 2006.

VAN DEN BOSSCHE, Peter. The Law and Policy of the World Trade Organization: text, cases and materials. New York: Cambridge University Press, 2005.

WTO. World Trade Organization. Understanding the WTO: the Organization - Members and Observers. Disponível em: $<\mathrm{http}: / / \mathrm{www}$. wto.org/english/thewto_e/whatis_e/tif_e/org6_e .htm>. Acesso em: 30 jun. 2012a.

Statistics Database. Disponível em: <http://http://stat.wto.org/>. Acesso em: 16 jul. 2012b.

Dispute Settlement: The Disputes - Chronological list of disputes cases. Disponível em: <http://www.wto.org/english/tratop_e/dispu_e/ dispu_status_e.htm>.Acesso em: 16 jul.2012c.

Dispute Settlement: Dispute DS267. United States - Subsidies on Upland Cotton. Disponível em: <http://www.wto.org/english/tratop_e/ dispu_e/cases_e/ds267_e.htm>.Acesso em: 17 jul.2012d.

RUSSIA TODAY. Russia officially joins World Trade Organization. Russia Today, Moscou, 21 jul. 2012. Disponível em: <http://rt.com/ politics/russia-putin-wto-joins-755/>. Acesso em: 21 jul. 2012. 